\title{
As trilhas ecológicas para o ensino de ciências na educação básica: olhares da perspectiva docente
}

\author{
José Renato de Oliveira Pin' (1D \\ Marcelo Borges Rocha" (D
}

RESUMO

As trilhas ecológicas materializam espaços educativos potenciais ao processo de ensino-aprendizagem. Assim, este estudo teve por objetivo investigar as contribuições didático-pedagógicas das trilhas ecológicas por meio da compreensão de 22 professores de Ciências, Biologia, Física e Química da educação básica de 16 municípios do estado do Espírito Santo. À luz da metodologia pesquisa-ação, foi evidenciado que as trilhas constituem espaços não formais singulares, uma vez que proporcionam a mediação do conhecimento in situ, ao ar livre (sem paredes, sujeito a intempéries e surpresas), o que impele os educadores a um olhar acurado sobre o planejamento de sua prática e sobre as atividades propostas antes e depois da realização do campo (vivência na trilha). A pesquisa permitiu concluir que as trilhas corroboram com a autonomia docente, configuram uma possibilidade didático-pedagógica motivadora e contribuem para a construção e/ou a consolidação de valores socioambientais salutares.

PALAVRAS-CHAVE

trilha ecológica; percepção docente; fazer didático-pedagógico. 


\title{
ECOLOGICAL TRAILS FOR SCIENCE TEACHING IN BASIC EDUCATION: LOOK FROM THE TEACHER PERSPECTIVE
}

\begin{abstract}
Ecological trails materialize potential educational spaces for the teachinglearning process. Thus, this study aims to investigate the didactic-pedagogical contributions of ecological trails based on the understanding of 22 teachers of Science, Biology, Physics, and Chemistry of the Basic Education of 16 municipalities from state of Espírito Santo. In light of the action-research methodology, it was evidenced that the trails constitute singular non-formal spaces, since they provide the mediation of knowledge in situ, outdoors (without walls, subject to weather and surprises), which impels educators to an accurate look at the planning of their practice and at the activities before and after the field (experience on the trail). The research concluded that the trails corroborate teaching autonomy, configure a motivating didactic-pedagogical possibility and contribute to the construction and/or consolidation of salutary social and environmental values.
\end{abstract}

KEYWORDS

ecologic trail; teaching perception; didactic-pedagogical practice.

\section{USO DE SENDEROS ECOLÓGICOS PARA LA EDUCACIÓN EN CIENCIAS EN LA EDUCACIÓN BÁSICA: MIRADAS DESDE LA PERSPECTIVA DOCENTE}

\section{RESUMEN}

Los senderos ecológicos materializan espacios educativos potenciales para el proceso enseñanza-aprendizaje. Así, este estudio tiene como objetivo investigar las contribuciones didáctico-pedagógicas de los senderos ecológicos en la enseñanza de las ciencias, con base en la comprensión de veintidós profesores de Ciencias, Biología, Física y Química de la educación básica, en dieciséis municipios brasileños. A la luz de la metodología investigación-acción se evidenció que los senderos constituyen espacios no formales singulares, ya que proporcionan la mediación del conocimiento in situ, al aire libre (sin paredes, sujeto al clima y sorpresas), lo que impulsa a los educadores la planificación de su práctica y atención a las actividades propuestas antes y después del campo (experiencia en el sendero). La investigación concluyó que los senderos corroboran la autonomía docente, configuran una posibilidad didáctico-pedagógica motivadora y contribuyen a construcción y/o consolidación de valores sociales y ambientales saludables.

PALABRAS CLAVE

sendero ecológico; percepción docente; hacer didáctico-pedagógico. 


\section{INTRODUÇÃO}

No contexto de uma educação para a vida em sociedade pautada em princípios que favoreçam o indivíduo a uma autonomia crítica e não fechada em si, a educação consolida-se em nossa contemporaneidade como proposta de formação humana importante sobre diferentes aspectos sociais, dos quais destacamos o cognitivo, o cultural e o inter-relacional. Desse modo, o processo formativo do educando utilizando espaços não formais pode ser favorecido pela construção individual e coletiva de atitudes, conceitos e procedimentos que produzirão indivíduos mais conscientes e críticos.

Nessa perspectiva, o trabalho docente que usa espaços-tempos que rompem a lógica diâmetro-comportamental do espaço escolar propicia uma práxis o mais contextual e abrangente possível. Os educandos nos espaços não formais têm a oportunidade da vivência com o real da materialidade, com a fusão da teoria com a prática e com o ingrediente da socialização. Para Marandino et al. (2003) e Jacobucci, Nogueira-Ferreira e Santana (2013), conforme o ponto de vista pedagógico, os espaços não formais intermedeiam a relação de aprendizagem na medida em que propõem interlocução entre o sujeito e dado objeto de estudo.

Jacobucci, Nogueira-Ferreira e Santana (2013) destacam que muitos conhecimentos tipicamente acadêmicos são de forma híbrida construídos fora da escola em espaços não formais. Em termos didáticos, para conceituar a expressão espaços não formais, amparamo-nos ao que nos apresenta Jacobucci (2008, p. 56-57):

No intuito de buscar uma definição para espaço não-formal, é importante conceituar o que é espaço formal de Educação. $O$ espaço formal é o espaço escolar, que está relacionado às Instituições Escolares da Educação Básica e do Ensino Superior, definidas na Lei 9394/96 de Diretrizes e Bases da Educação Nacional. É a escola, com todas as suas dependências: salas de aula, laboratórios, quadras de esportes, biblioteca, pátio, cantina, refeitório. [...]. Voltemos agora à tentativa de definir os espaços não-formais de Educação. Duas categorias podem ser sugeridas: locais que são Instituições e locais que não são Instituições. $\mathrm{Na}$ categoria Instituições, podem ser incluídos os espaços que são regulamentados e que possuem equipe técnica responsável pelas atividades executadas, sendo o caso dos Museus, Centros de Ciências, Parques Ecológicos, Parques Zoobotânicos, Jardins Botânicos, Planetários, Institutos de Pesquisa, Aquários, Zoológicos, dentre outros. Já os ambientes naturais ou urbanos que não dispõem de estruturação institucional, mas onde é possível adotar práticas educativas, englobam a categoria Não-Instituições. Nessa categoria podem ser incluídos teatro, parque, casa, rua, praça, terreno, cinema, praia, caverna, rio, lagoa, campo de futebol, dentre outros inúmeros espaços.

Nessa ótica, é possível compreender as trilhas ecológicas inseridas em áreas verdes florísticas como potenciais espaços não formais bastante significativos à operacionalização de práticas pedagógicas voltadas ao ensino de ciências, especialmente aquelas de caráter interdisciplinar. Situado sobre um olhar paisagístico, as 
trilhas corporificam corredores de diferentes formatos, construídos antropicamente em meio à determinada área vegetada. Elas configuram meandros experienciais estimulantes ao desenvolvimento cognitivo, tanto do ponto de vista conceitual quanto do ponto de vista sociocultural.

Conforme Rendeiro, Santos Júnior e Fachin-Terán (2012), o grande atrativo de uma trilha ecológica é mesmo o próprio ambiente que a envolve, em muitos casos ambientes de floresta, onde as trilhas sem pavimentação inserem o visitante em meandros florísticos com toda uma fauna e flora livres. Para esses autores, as trilhas podem ser exploradas por um viés recreativo e educativo, pois seus atributos paisagísticos constituem elementos propícios à interpretação polissêmica do ambiente natural.

Assim, a imersão ambiental proporcionada pela caminhada ao longo de uma trilha, quando planejada cuidadosamente, assume papel de destaque na formação e consolidação de uma consciência sensível às questões da natureza, sobretudo do fator humano que de alguma forma as envolve.

Para Pin e Campos (2015), uma característica marcante das trilhas ecológicas é a possibilidade de interação que estabelecem com os seus visitantes, principalmente do público escolar, uma vez que despertam curiosidades e colaboram para apropriações relativas à educação ambiental e científica. As trilhas inseridas em unidades de conservação (UCs), por exemplo, como aquelas presentes em parques florestais, reservas biológicas e florestas nacionais, perfazem percursos guiados e autoguiados que aguçam os sentidos humanos objetivando visualizar, perceber, sentir, interpretar e melhor compreender os processos autossustentáveis do equilíbrio ecológico.

Conforme destacam Rocha et al. (2016) e Pin et al. (2016), para a educação em ciências, as trilhas ecológicas constituem mais uma possibilidade de prática pedagógica, contudo distinta daquelas que ocorrem na escola, necessitando para isso que o professor identifique suas potencialidades pedagógicas, busque adequar metodologias e verifique o modo como esses locais contribuem nas complexificações de conhecimentos.

Para Menghini (2005), as trilhas integram um espaço de educação não formal que muito auxilia nas atitudes socialmente salutares, bem como na lapidação de assuntos abordados no ensino formal em sala de aula. Para a autora, os ganhos com a realização de atividades nesses espaços têm relação direta com um planejamento que contemple preferencialmente um trabalho interdisciplinar por parte dos profissionais de ensino.

Diante dessa necessidade, este estudo teve por objetivo principal investigar as contribuições didático-pedagógicas das trilhas ecológicas no ensino de ciências por meio da compreensão de 22 professores atuantes nas disciplinas de Ciências, Biologia, Física e Química da educação básica de 16 municípios do estado do Espírito Santo (Brasil). Ficou entendido aqui o ensino de ciências como o ensino acerca de conhecimentos biológicos, físicos, químicos e geocientíficos articulados a outras áreas de conhecimento, tais como saúde, economia, sociologia, política, entre outras.

Vale salientar que a investigação com os docentes partiu da ideia de que as trilhas - conceitualmente definidas como percurso geográfico construído histórica e culturalmente no interior de áreas verdes florísticas e compreendido sob potencialidades 
didático-pedagógicas - materializam uma possibilidade de espaço não formal viável e eficiente para práticas didático-pedagógicas contextualizadas e interdisciplinares. Ademais, esses espaços florísticos, a priori, vêm de encontro a possíveis concepções corruptíveis, tais como: trilha é só para tratar de conteúdos correlatos à biologia, trilha deve ser utilizada eventualmente para aula de campo, trilha como sinônimo de passeio despretensioso etc.

\section{PERCURSO METODOLÓGICO}

Ao se colocar em discussão o uso de trilhas ecológicas no ensino de ciências tendo como protagonista de discursos e olhares professores atuantes em disciplinas da área das ciências da natureza, encontramos no pensamento e na discussão coletiva uma possibilidade de formação docente de caráter epistêmico e prático.

Nesse bojo, todo o processo de transformação do conhecimento humano depende fundamentalmente da apresentação de propostas que coloquem em pauta novas maneiras de desenvolver o objeto posto em discussão ou pensar sobre ele. Segundo Nunes e Infante (1996), ações implementadas de forma hierárquica, oriundas de processos não dialógicos e não reflexivos entre os indivíduos envolvidos, se tornam medidas isoladas, responsáveis pelo desenvolvimento estanque e temporário de um setor ou outro, sem, contudo, alterar o desempenho global de um grupo ou de uma organização.

Atento a esse fato, Tripp (2005) destaca a importância de reconhecer o método de pesquisa-ação como um tipo de investigação-ação que leva à transformação epistemológica e, por conseguinte, à prática. Para o autor, investigação-ação é um termo genérico aplicado a processos que seguem um ciclo, no qual se aprimora a prática pela oscilação sistemática entre a ação (no campo prático) e a investigação (no campo epistemológico reflexivo). $\mathrm{Na}$ busca de mudanças de práticas e processos que avancem em eficiência e eficácia, metodologicamente a investigação-ação começa com a identificação de dado problema, o planejamento e a implementação de uma possível solução, seu monitoramento e a avaliação de sua eficácia. Um processo que, ao todo, busca a melhor compreensão sobre dada situação de investigação, a fim de que sua prática seja melhorada.

Segundo Nunes e Infante (1996), a metodologia da pesquisa-ação busca desenvolver técnicas e conhecimentos necessários ao fortalecimento das atividades desenvolvidas. Utilizando elementos/elaborações dos próprios participantes, por meio da valorização do seu saber e da sua prática diária, e aliando-os aos conhecimentos teóricos e às experiências adquiridos pelos pesquisadores, essa metodologia produz um novo saber capaz de apontar propostas a problemas inicialmente levantados. Os autores salientam que a pesquisa-ação exige do grupo pesquisado gestão participativa, motivação, trabalho em equipe, transparência nas informações, delegação de poder e iniciativa, a fim de proporcionar a participação efetiva de todos os membros envolvidos. Vale destacar que no processo de gestão participativa a iniciativa para a ação, para a criação, para a revisão das práticas e dos hábitos para o novo precisa ser respeitada, compreendida e estimulada por todos. 
De acordo com Thiollent $(1999,2011)$ a pesquisa-ação deve estabelecer uma relação engendrada entre conhecimento e ação, entre pesquisadores e pessoas implicadas na situação investigada e de ambos com a realidade. Para o autor, a ampla e explícita interação entre os pesquisadores e os sujeitos envolvidos na pesquisa não pode se limitar a uma forma de ação desapropriada de construção ideológica (risco de ativismo). Pontuado tal risco, a pesquisa-ação busca aumentar o conhecimento dos pesquisadores e o conhecimento ou nível de consciência das pessoas e dos grupos que participam do processo, contribuindo, assim, para a discussão ou fazendo avançar o debate acerca das questões elencadas.

Thiollent $(1999,2011)$ ainda enfatiza que uma pesquisa pode ser qualificada como pesquisa-ação quando houver de fato uma ação por parte das pessoas ou dos grupos implicados no problema sob observação. Além disso, reforça que a ação é uma ação não trivial, o que quer dizer que se trata de uma ação problematizada merecendo investigação para ser elaborada e conduzida. Tripp (2005) e Thiollent (2011) chamam a atenção para o fato de que na pesquisa-ação o pesquisador busca integrar-se ao contexto dos sujeitos pesquisados na intencionalidade de exercer uma ação politica de transformaçã̃o do grupo.

Para Freire (1984), na área educacional, a pesquisa-ação investiga a "realidade concreta", diante de problemas enfrentados na prática docente (políticos e ideológicos, e não apenas epistemológicos, pedagógicos ou das ciências sociais). $\mathrm{Na}$ dialética do pensamento, conhecimento e prática, esse método permite fazer da ação uma prática criticamente pensada (práxis), que funde e integra teoria e ação. No entender do autor, fazendo pesquisa-ação, o pesquisador educa e está ao mesmo tempo educando-se. Ao colocar em prática os resultados da pesquisa, ele está pesquisando outra vez, em um permanente e dinâmico movimento de pesquisa e de formação. Moreira (2003) destaca que as pesquisas em educação e, por extensão, em ensino, de maneira bem abrangente, têm seu fenômeno de interesse a ver com o ensino, a aprendizagem, a avaliação, o currículo e o contexto. Questões metodológicas acerca das aulas, procedimentos de avaliação, novas propostas curriculares, influência de certa variável sobre a aprendizagem e percepções mútuas de alunos e professores são exemplos de fenômenos que interessam à pesquisa em ensino.

Nesse sentido, a pesquisa-ação fomenta o envolvimento ativo dos integrantes do contexto escolar na superação de seus problemas, descrevendo, problematizando, conjecturando possibilidades e desenvolvendo ações, pois consiste na realização bem amadurecida do fazer didático-pedagógico subsecutivo ao pensamento críticoreflexivo sobre ele.

Ao olharmos para o campo metodológico da pesquisa-ação, Lewin (1946), Queiroz et al. (2012), Rosa (2013) e Thiollent (2011) enfatizam a necessidade de definir, com precisão, os objetivos e obstáculos da pesquisa, os agentes envolvidos e a exigência a respeito dos conhecimentos produzidos, ao considerar a ação desenvolvida. Os autores salientam que a participação dos pesquisadores é evidenciada no processo do conhecer com os cuidados necessários para que haja reciprocidade e complementariedade por parte dos sujeitos pesquisados, que têm algo a dizer e a fazer, afinal não se trata de um simples levantamento de dados. 
Tomando por base Lewin (1946), Queiroz et al. (2012), Rosa (2013), Tripp (2005) e Thiollent (2011) e pensando em termos metodológicos, delineamos quatro etapas orientadoras do desenvolvimento da pesquisa-ação, que, por sua vez, se encontram ancoradas subjacentemente na questão da intencionalidade de transformação estimulada pelo pesquisador. Essas etapas não configuram fases herméticas, pontuais ou estanques, mas aportes que buscam traçar caminhos para o desenvolvimento desse tipo de pesquisa. São elas:

- Montagem institucional e metodológica;

- Fase exploratória;

- Análise crítica dos problemas considerados prioritários;

- Construção, aplicação e avaliação de um plano de ação.

No Quadro 1 apresentamos as características gerais de cada uma dessas fases.

Quadro 1 - Características gerais de cada etapa orientadora do desenvolvimento da pesquisa-ação.

\begin{tabular}{|l|l|}
\hline \multicolumn{2}{|c|}{ Etapas orientadoras do desenvolvimento da pesquisa-ação } \\
\hline $\begin{array}{l}\text { Montagem } \\
\text { institucional e } \\
\text { metodológica }\end{array}$ & $\begin{array}{l}\text { O pesquisador discute o projeto de pesquisa com seus pares e com representantes } \\
\text { do seu público-alvo, estabelece possíveis parcerias institucionais, prepara o } \\
\text { quadro teórico e o cronograma metodológico (ambos passíveis de alterações e } \\
\text { ajustes) e define a área de atuação, o público-alvo e as formas de fomento. }\end{array}$ \\
\hline Fase exploratória & $\begin{array}{l}\text { O pesquisador procura identificar as características dos sujeitos que constituem o } \\
\text { grupo de estudo e conhecer suas percepções quanto ao objeto de pesquisa. Trata- } \\
\text { se do momento em que o pesquisador tem contato com os sujeitos pesquisados } \\
\text { e acesso ao seu universo sociocultural. Nesta fase se evidencia o universo dos } \\
\text { pesquisados e se faz o levantamento de dados considerados relevantes à pesquisa. }\end{array}$ \\
\hline $\begin{array}{l}\text { Análise crítica } \\
\text { dos problemas } \\
\text { considerados } \\
\text { prioritários }\end{array}$ & $\begin{array}{l}\text { Os sujeitos envolvidos, distribuídos em grupos de estudo e discussão, devem } \\
\text { analisar criticamente os problemas acerca do objeto de pesquisa, confrontar e } \\
\text { convergir ideias, tendo em vista possíveis estratégias de superação. }\end{array}$ \\
\hline $\begin{array}{l}\text { Construção, } \\
\text { aplicação e } \\
\text { avaliação de um } \\
\text { plano de ação }\end{array}$ & $\begin{array}{l}\text { As ações que foram delineadas nas etapas anteriores são organizadas a fim de } \\
\text { resultar na construção colaborativa (pesquisador e sujeitos pesquisados) de um } \\
\text { plano de ação. Ao executar esse plano, busca-se a ação organizada, que requer } \\
\text { autoinvestigação dos sujeitos, reflexão crítica sobre sua própria realidade e procura } \\
\text { de ações que a transformem. Posteriormente à execução do plano de ação, ocorre a } \\
\text { avaliação, quando então os resultados são elencados e discutidos por todos. Dessa } \\
\text { forma, os conhecimentos produzidos pela pesquisa possibilitarão ao pesquisador e } \\
\text { aos sujeitos pesquisados (re)elaborarem sua prática. }\end{array}$ \\
\hline
\end{tabular}

Vale salientar que, ao final das quatro etapas delineadas para a pesquisa-ação, os resultados alcançados visam à transformação de uma situação-problema em seu campo epistemológico e prático, produzindo, em todos os envolvidos, novas acepções. Com isso, ocorrem possibilidades de outros projetos, de novas pesquisas.

Ao desenvolvermos um curso de extensão universitária voltado a professores de ciências da educação básica, partimos do pressuposto de que no contexto do ensino a pesquisa-ação se apresenta como uma metodologia capaz de desenvolver e lapidar questões dos campos teórico e prático. $\mathrm{O}$ curso, intitulado Espaços 
Educativos Não Formais no Ensino de Ciências: as Trilhas Ecológicas em Debate, buscou discutir e erigir apropriações acerca das potencialidades e especificidades didático-pedagógicas das trilhas ecológicas no ensino de ciências, objeto principal de estudo neste trabalho. Tomando como referência as etapas descritas no Quadro 1, o curso apresentou as seguintes etapas:

- Montagem institucional e metodológica: configuraram-se a construção teórica e metodológica do curso, sua validação por professores pesquisadores da área de ensino de ciências do Centro Federal de Educação Tecnológica Celso Suckow da Fonseca, do Rio de Janeiro (CEFET/RJ), e a efetivação de parcerias institucionais para sua aplicação no Instituto Federal do Espírito Santo (IFES) campus Cachoeiro de Itapemirim (ES). Importante dizer que para a construção teórica e metodológica se levaram em consideração compreensões e opiniões sobre o objeto principal de estudo, manifestadas por professores da região geográfica abrangida pelo curso no período de agosto a outubro de 2016 (sondagem realizada por meio de conversas informais em escolas e durante visitas educativas no Parque Estadual Mata das Flores);

- Fase exploratória: envolveu os momentos em que o pesquisador e os sujeitos pesquisados (professores) se apresentaram, expuseram suas expectativas, adequaram o cronograma do curso (podendo sugerir alterações de ordem cronológica e de materiais de estudo) e se aplicou o questionário diagnóstico aos professores;

- Análise crítica dos problemas considerados prioritários: ocorreu quando pesquisador e os professores apontaram questões de estudo acerca do uso de trilhas ecológicas no ensino de ciências, suscitando opiniões divergentes, convergentes e inusitadas. Por conseguinte, geraram-se problematizações, correlações, conjecturas e possibilidades organizacionais que estimularam, sob medidas distintas, o pensamento reflexivo, crítico e ético dos participantes envolvidos (pesquisador e professores). Esta etapa utilizou ricamente atividades produzidas em subgrupos de estudo e discussão, que, oportunamente, levaram suas considerações à discussão em plenária;

- Construção, aplicação e avaliação de um plano de ação: deram-se quando os professores, em subgrupos, produziram propostas de atividades didático-pedagógicas considerando os problemas discutidos na etapa anterior. Validaram essas propostas na plenária e posteriormente as aplicaram durante uma aula de campo em uma trilha ecológica. Logo, pesquisador e professores pontuaram e avaliaram os resultados dessa prática, a fim de produzir novos significados sobre o uso de trilhas ecológicas no ensino de ciências. Cada proposta de atividade correspondeu a um plano de ação, fruto de um trabalho coletivo, colaborativo e reflexivo.

Destacamos que o principal critério na definição da pesquisa-ação como metodologia orientadora do transcurso desta pesquisa se pauta na consonância 
de que tanto a metodologia pesquisa-ação quanto a própria pesquisa - objeto de estudo apresentado neste manuscrito - buscam promover uma transformação epistemológica pari passu metodológica, mediante o envolvimento dialógico e produtivo entre pesquisador e pesquisados.

\section{COLETA E ANÁLISE DE DADOS}

No contexto de uma pesquisa em que a participação e o envolvimento entre pesquisador e pesquisados são premissas fundamentais, a coleta de materiais para análise ocorreu durante a realização do curso de extensão universitário Espaços Educativos Não Formais no Ensino de Ciências: as Trilhas Ecológicas em Debate. Desse modo, foram utilizados três instrumentos de coleta:

- Atividades de aulas: atividades relacionadas ao uso de trilhas ecológicas no ensino de ciências e produzidas pelos professores ao longo dos encontros presencias;

- Relatórios finais: relatórios produzidos individualmente ou em subgrupos pelos professores, como requisito de conclusão do curso;

- Registros em diário de campo: registros graficamente produzidos pelo pesquisador com base nas gravações em áudio de todos os oito encontros presenciais ocorridos.

Vale pontuar que os registros em diário de campo configuram anotações de percepções e compreensões do pesquisador, bem como transcrições de falas dos professores pesquisados.

Também, foi aplicado o instrumento questionário misto (com questões abertas e fechadas) individualmente aos professores no início do curso para a caracterização geral do grupo. Ainda, registros fotográficos foram produzidos ao longo de todo o curso, a fim de mostrar e/ou exemplificar momentos vivenciados.

Assim, o corpus documental foi constituído de 17 atividades de aula (propostas de plano de ação e atividades diversificadas produzidas coletivamente), codificadas de AA1, AA2, AA3, ..., AA17; por 12 relatórios finais, chamados de $\mathrm{RF} 1, \mathrm{RF} 2, \mathrm{RF} 3, \ldots, \mathrm{RF} 12$; e por 301 registros em diário de campo, denominados de RDC1, RDC2, .., RDC301.

Concernente às atividades de aula, especificam-se: cinco propostas de plano de ação produzidas no quarto encontro presencial do curso de extensão universitária, codificados de AA1 a AA5; cinco atividades diversificadas produzidas no terceiro encontro, denominadas de AA6 a AA10; cinco atividades diversificadas produzidas no quarto encontro - AA11 a AA15 -; e duas atividades diversificadas produzidas no sexto encontro, AA16 e AA17. Ao que se refere aos relatórios finais, foram dez trabalhos produzidos em dupla e dois de maneira individual.

Os materiais coletados foram analisados com base nos pressupostos da análise de conteúdo discorridos em Bardin (2016). Para essa autora, a análise de conteúdo é um conjunto de técnicas de apreciação analítica de textos, entrevistas, imagens, comunicações, cujo objetivo é ultrapassar as incertezas e enriquecer a leitura dos dados. Para Bardin (2016), a análise de conteúdo consiste em: 
Um conjunto de técnicas de análise das comunicações, que utiliza procedimentos sistemáticos e objetivos de descrição do conteúdo das mensagens. [...] A intenção da análise de conteúdo é a inferência de conhecimentos relativos às condições de produção (ou, eventualmente, de recepção), inferência esta que recorre a indicadores (quantitativos ou não). (Bardin, 2016, p. 44)

Nessa ótica, a análise de conteúdo oferece suporte metodológico para compreender criticamente o sentido das comunicações, do seu conteúdo manifesto ou latente, das significações explícitas e implícitas, a fim de ampliar em uma leitura pormenorizada o sentido do que está sendo dito a respeito do tema pesquisado.

Numa análise de conteúdo, o importante não é a descrição pura e simples dos conteúdos das mensagens, mas as ideias que elas podem transmitir e ensinar, a fim de se obter significados sobre as mensagens. A escolha dessa metodologia para a produção e a análise dos dados nesta pesquisa se deve ao fato de que sua operacionalização e estruturação permitem identificar e complexificar elementos contextuais explicitados pelos pesquisados (professores da educação básica). Desse modo, é possível produzir novas perspectivas e novos olhares sobre o objeto principal do estudo em questão.

Entendendo a análise de conteúdo como uma metodologia de dimensão analítica bastante complexa e arraigada de subjetividades, natural do fazer ciência, Bardin (2016) apresenta três fases que direcionam o pesquisador metodologicamente:

- Pré-análise;

- Exploração do material;

- Tratamento dos resultados, inferência e interpretação.

$\mathrm{Na}$ fase de pré-análise é realizada uma leitura flutuante dos materiais coletados, a fim de identificar e selecionar aqueles que, de fato, se relacionem à pesquisa. Esses materiais triados passam a ser denominados de documentos, e seu conjunto constitui o que chamamos de corpus documental. Efetivamente, a leitura flutuante é uma atividade indicada nessa fase inicial da pesquisa, pois tem os intuitos de conhecer os materiais coletados e criar as primeiras impressões sobre o tema pesquisado. Aqui se estabelecem as hipóteses emergentes, os objetivos, as dimensões e as direções da pesquisa.

$\mathrm{Na}$ etapa de exploração do material é feita uma leitura mais precisa dos documentos, pois do corpus documental são selecionados os elementos considerados relevantes à pesquisa, avaliados como significativos ao estudo proposto. Logo, produzem-se do corpus documental os dados brutos da pesquisa. Nessa fase também se procedem a duas operações: a codificação e a categorização. A codificação consiste em separar os dados brutos considerando-os individualmente como unidades. Nesta pesquisa as unidades são do tipo unidades de contexto, por se tratar de trechos (segmentos) de mensagens nas quais se buscou analisar os sentidos e as compreensões ali expressos. No tocante à operação de categorização, esta consiste em formar um sistema classificatório de análise composto de categorias e possíveis subcategorias (ramificações das primeiras), no qual as unidades de contexto são alocadas associativamente. Como um todo, a fase de 
exploração do material exige do pesquisador a administração sistemática quanto às decisões e operacionalizações tomadas.

Depois de efetuadas as duas primeiras fases, chega o momento em que os dados brutos são tratados de maneira a serem significativos e válidos. De modo conjunto, o tratamento dos resultados, as inferências e as interpretações ocorrem praticamente ao mesmo tempo e consistem em dispor os resultados produzidos, em propor inferências e em posicionar interpretações a propósito dos objetivos inicialmente estabelecidos na pesquisa, ou que digam respeito a outras descobertas inesperadas.

A natureza da análise de conteúdo empregada sobre os materiais coletados, conforme Bardin (2016), se dá por meio de uma abordagem qualitativa, ressaltandose que elementos quantificáveis também foram utilizados a fim de tonificar o tratamento desenvolvido. Conforme atentam Gonçalves et al. (2014), a pesquisa de caráter qualitativo compreende diferentes meios interpretativos que visam explicitar os componentes de um sistema complexo, produzidos com base nos documentos coletados. Para esse tipo de abordagem, utilizam-se procedimentos descritivos e conectivos que possibilitam analisar as falas, os discursos, os escritos, de forma a relacionar informações à realidade de contextos sociais.

\section{QUADRO DE ANÁLISE DE CONTEÚDO}

O quadro de análise de conteúdo, também denominado de quadro analítico, é um instrumento gráfico que fornece uma conjectura objetiva da fase de exploração do material, como também subsidia o desenvolvimento da fase analítica seguinte.

Para Bardin (2016), o quadro de análise de conteúdo deve ser constituído no desenvolvimento das operações de codificação e categorização e sob duas estruturas principais: os indicadores de ocorrências, em que se apontam quantitativamente as unidades de contexto; e as categorias, nas quais se expõem as dimensões analisadas pela pesquisa. A autora também ressalta a possibilidade de uma terceira estrutura: as subcategorias, em que se especificam e se diluem as dimensões que são expostas nas categorias, buscando tornar a análise das unidades de contexto mais fácil de se perceber.

Ao considerar os apontamentos, as compreensões e as discussões realizados pelos professores ao longo do curso de extensão universitária, foi produzido um quadro de análise de conteúdo com base em três categorias de análise: planejamento escolar, potencialidades didático-pedagógicas e especificidades do ambiente.

A categoria planejamento escolar coloca em relevância apontamentos que devem ser levados em consideração pelo professor e pela equipe escolar no momento do planejamento escolar, ou seja, ainda na fase preparatória da aula de campo propositada para uma trilha ecológica. Essa categoria foi dividida em duas: aspectos burocráticos e aspectos pedagógicos. $\mathrm{Na}$ subcategoria aspectos burocráticos, atentamos a questões organizacionais e institucionais ligadas à exequibilidade operacional da aula. Na subcategoria aspectos pedagógicos, por sua vez, verificamos questões que se referem à preparação teórica e ao possível envolvimento cognitivo dos estudantes à aula. 
Na sequência, a categoria potencialidades didático-pedagógicas busca evidenciar aspectos epistemológicos e interpessoais pelo uso de trilhas ecológicas no processo de ensino-aprendizagem em ciências. Essa categoria foi dividida em três: o ensino, a possibilidade de aprendizagem e questões interpessoais. Nas duas primeiras subcategorias analisamos a forma como os conteúdos (conceituais, procedimentais e emocionais) podem estar envolvidos no processo de ensino-aprendizagem, sejam por iniciativas do fazer docente (o ensino), sejam por possíveis interações com os estudantes (a possibilidade de aprendizagem). Na terceira subcategoria, denominada de questões interpessoais, atentamos para fatores sociorrelacionais ligados a aproximações ou distanciamentos entre professores, estudantes e condutores.

Já a categoria especificidades do ambiente procura destacar características próprias do ambiente físico das trilhas que se relacionam ao processo de ensino-aprendizagem de ciências, buscando um olhar mais acurado à trilha enquanto um percurso geográfico em ambiente florístico. Essa categoria foi dividida em: preconceitos e características próprias das trilhas. $\mathrm{Na}$ subcategoria preconceitos sobre trilhas ecológicas, atentamo-nos às concepções trazidas pelos professores por meio de suas próprias experiências ou experiências recolhidas por eles de outros membros da comunidade escolar. $\mathrm{Na}$ subcategoria características próprias do ambiente, constatamos as compreensões que ressaltam características próprias do ambiente natural e que, por sua materialidade, salientam fatores impactantes no desenvolvimento de práticas didáticas-pedagógicas.

\section{UM POUCO SOBRE O CURSO DE EXTENSÃO UNIVERSITÁRIA}

O estudo para esta pesquisa configura-se em uma pesquisa-ação desenvolvida por meio do curso de extensão universitária Espaços Educativos Não Formais no Ensino de Ciências: as Trilhas Ecológicas em Debate, promovido pelo IFES campus Cachoeiro de Itapemirim. Esse curso teve como objetivo principal discutir as potencialidades didático-pedagógicas das trilhas ecológicas para o ensino escolar das ciências numa perspectiva sociointeracionista e contextual. Ao longo do seu desenvolvimento, foi constituído um espaço-tempo de estudo e discussões no qual as trilhas ecológicas foram tratadas como possível espaço educativo não formal alinhado às perspectivas de um ensino de ciências contemporâneo. Seu público-alvo foram professores da educação básica das disciplinas de Ciências, Biologia, Física e Química de municípios localizados nas microrregiões central-sul, sudeste-serrana, litoral-sul e Caparaó do estado do Espírito Santo.

$\mathrm{Na}$ oportunidade, é lícito justificar a escolha geográfica das microrregiões supracitadas para o desenvolvimento deste trabalho. $\mathrm{O}$ primeiro ponto refere-se ao fato de que o pesquisador, além de apresentar interesse de ordem pessoal pelo assunto, também tem interesse profissional, uma vez que compõe o quadro efetivo de professores de Ciências da rede de ensino do município de Castelo, localizado na microrregião central-sul do Espírito Santo. O segundo ponto diz respeito ao fato de que, nos 34 municípios que compõem as microrregiões mencionadas anteriormente, há apenas cinco museus categorizados como centros ou museus de ciências. Conforme informado pelo Instituto Brasileiro de Museus (IBRAM, 2011) e pela 
Rede Nacional de Identificação de Museus (RENIM, 2017), um deles é o Museu de História Natural do Sul do Espírito Santo, localizado no município de Jerônimo Monteiro, e os outros quatro personificam quatro UCs do tipo parque florestal: Parque Estadual de Pedra Azul, no município de Domingos Martins; Parque Estadual Cachoeira da Fumaça, em Alegre; Parque Estadual Mata das Flores, em Castelo; e Parque Estadual de Forno Grande, também em Castelo.

Ao considerarmos a quantidade total de UCs inseridas nas microrregiões central-sul, sudeste-serrana, litoral-sul e Caparaó do Espírito Santo, encontramos uma gama de áreas verdes abertas à visitação pública e passíveis de serem compreendidas enquanto espaços não formais potenciais ao ensino de ciências. São elas: Floresta Nacional de Pacotuba, Reserva Particular do Patrimônio Natural Fazenda Cafundó, Reserva Particular do Patrimônio Nacional Mata da Serra, Monumento Natural o Frade e a Freira, Monumento Natural Serra das Torres, Parque Natural Municipal do Itabira, Parque Nacional do Caparaó, entre tantas outras. Assim, acreditamos que, ao discutir e fomentar as trilhas ecológicas como espaços educativos privilegiados a práticas didático-pedagógicas, estamos contribuindo para um ensino de ciências mais dinâmico e contextual, aliado às potencialidades naturais das microrregiões como um todo.

A divulgação do curso de extensão universitária ocorreu no período de 6 de março a 6 de abril de 2017 por meio de edital disponibilizado no site oficial do IFES e emissão de correspondência oficializada pelo IFES às secretarias municipais de Educação da região.

No período de 10 de abril a 19 de junho de 2017, o curso, oferecido de forma gratuita e por adesão voluntária, foi desenvolvido ao longo de oito encontros presenciais, os quais totalizaram carga horária de 36 horas, realizadas conforme cronograma apresentado no Quadro 2. Ademais, sob modalidade não presencial, foram reservadas 24 horas para leituras de textos-base e produção de relatório final. Exceto o quinto encontro, ocorrido na trilha ecológica do Santuário, todos os demais aconteceram no auditório do bloco B5 do IFES campus Cachoeiro de Itapemirim, no período de 18h às 22h30.

Quadro 2- Cronograma do curso de extensão universitária Espaços Educativos Não Formais no Ensino de Ciências: as Trilhas Ecológicas em Debate, desenvolvido em 2017.

\begin{tabular}{|l|c|c|c|l|}
\hline Encontro & Local & Horário & Data & \multicolumn{1}{|c|}{ Conteúdos e atividades } \\
\hline 1 & $\begin{array}{c}\text { IFES } \\
\text { Cachoeiro de } \\
\text { Itapemirim }\end{array}$ & $\begin{array}{c}18 \mathrm{~h} \\
\text { às } \\
22 \mathrm{~h} 30\end{array}$ & $10 / 4$ & $\begin{array}{l}\text { Apresentação do curso e acolhimento de } \\
\text { considerações. Perfil do grupo participante. O ensino } \\
\text { de ciências no contexto da educação científica. } \\
\text { Questões sobre CTS no ensino de Ciências. }\end{array}$ \\
\hline 2 & $\begin{array}{c}\text { IFES } \\
\text { Cachoeiro de } \\
\text { Itapemirim }\end{array}$ & $\begin{array}{c}18 \mathrm{~h} \\
\text { às } \\
22 \mathrm{~h} 30\end{array}$ & $17 / 4$ & $\begin{array}{l}\text { Implicaçães da alfabetização e divulgação } \\
\text { científica. Espaços educativos formais e não } \\
\text { formais: conceitos e potencialidades. }\end{array}$ \\
\hline $\begin{array}{c}\text { IFES } \\
\text { Cachoeiro de } \\
\text { Itapemirim }\end{array}$ & $\begin{array}{c}18 \mathrm{~h} \\
\text { às } \\
22 \mathrm{~h} 30\end{array}$ & $8 / 5$ & $\begin{array}{l}\text { Aulas de campo como possibilidade para o ensino } \\
\text { de ciências. Aula de campo e temas geradores. } \\
\text { Elaboração de sequência de atividades com } \\
\text { inserção de trilha ecológica em uma de suas etapas. }\end{array}$ \\
\hline
\end{tabular}

Continua... 
Quadro 2-Continuação.

\begin{tabular}{|c|c|c|c|c|}
\hline Encontro & Local & Horário & Data & Conteúdos e atividades \\
\hline 4 & $\begin{array}{c}\text { IFES } \\
\text { Cachoeiro de } \\
\text { Itapemirim }\end{array}$ & $\begin{array}{c}18 \mathrm{~h} \\
\text { às } \\
22 \mathrm{~h} 30\end{array}$ & $15 / 5$ & $\begin{array}{l}\text { Uma trilha ecológica: espaço de condução e } \\
\text { interpretação ambiental. Planejamento para } \\
\text { aula de campo: aspectos disciplinares, afetivos } \\
\text { e comportamentais. Elaboração e validação } \\
\text { de planos de ação para aplicação em aula de } \\
\text { campo na Trilha Ecológica Trilha do Santuário } \\
\text { (Castelo/ES). }\end{array}$ \\
\hline 5 & $\begin{array}{l}\text { Parque } \\
\text { Estadual } \\
\text { Mata das } \\
\text { Flores }\end{array}$ & $\begin{array}{c}8 \mathrm{~h} \\
\text { às } \\
12 \mathrm{~h} 30\end{array}$ & $27 / 5$ & $\begin{array}{l}\text { Aula de campo na Trilha do Santuário } \\
\text { (Parque Estadual Mata das Flores, Castelo/ES). }\end{array}$ \\
\hline 6 & $\begin{array}{c}\text { IFES } \\
\text { Cachoeiro de } \\
\text { Itapemirim }\end{array}$ & $\begin{array}{c}18 \mathrm{~h} \\
\text { às } \\
22 \mathrm{~h} 30\end{array}$ & $29 / 5$ & $\begin{array}{l}\text { Avaliação pós-campo. Discussão da temática trilhas } \\
\text { ecológicas como espaços educativos não formais. }\end{array}$ \\
\hline 7 & $\begin{array}{c}\text { IFES } \\
\text { Cachoeiro de } \\
\text { Itapemirim }\end{array}$ & $\begin{array}{c}18 \mathrm{~h} \\
\text { às } \\
22 \mathrm{~h} 30\end{array}$ & $5 / 6$ & Orientação à produção de relatório final. \\
\hline 8 & $\begin{array}{c}\text { IFES } \\
\text { Cachoeiro de } \\
\text { Itapemirim }\end{array}$ & $\begin{array}{c}18 \mathrm{~h} \\
\text { às } \\
22 \mathrm{~h} 30\end{array}$ & $19 / 6$ & $\begin{array}{l}\text { Entrega do relatório final. Palestra de } \\
\text { encerramento Espaços de educaçấo não formal: } \\
\text { potencializando a educaçấo cidadã, com o } \\
\text { palestrante Marcos Antonio Sattler, doutor } \\
\text { em Produção Vegetal e coordenador do Polo } \\
\text { de Educação Ambiental da Mata Atlântica, } \\
\text { IFES Campus Alegre. }\end{array}$ \\
\hline
\end{tabular}

IFES: Instituto Federal do Espírito Santo; CTS: ciência, tecnologia e sociedade.

A pesquisa foi registrada no Ministério da Saúde via Plataforma Brasil, avaliada pelo Comitê de Ética da Universidade Federal do Estado do Rio de Janeiro, e obteve-se a aprovação.

\section{CARACTERIZAÇÃO GERAL DOS PROFESSORES PESQUISADOS}

O grupo pesquisado foi constituído de 22 professores da educação básica das disciplinas de Ciências, Biologia, Física e Química - 16 docentes do sexo feminino e seis do sexo masculino. Esses docentes lecionam em escolas de 16 cidades do estado do Espírito Santo, compondo representatividade dos municípios Alegre, Atílio Vivácqua, Cachoeiro de Itapemirim, Castelo, Conceição do Castelo, Domingos Martins, Ibatiba, Itapemirim, Marataízes, Mimoso do Sul, Muniz Freire, Muqui, Piúma, Rio Novo do Sul, Vargem Alta e Venda Nova do Imigrante. A fim de resguardar sua identidade, seus nomes foram codificados e são referidos ao longo do manuscrito como P1, P2, P3, ..., P22. São professores com idades entre 23 e 52 anos, contudo a maioria deles (15 integrantes) está na faixa etária de 23 a 30 anos. Nove deles nunca havia, até a realização do curso, tido experiência em aula de campo (fosse como organizador, fosse como discente), e oito relataram já ter tido experiência em aula de campo em trilhas ecológicas. 
No tocante ao nível de escolaridade em sua maior titulação, são dez professores graduados, oito especialistas, três mestres e um doutor. Todos apresentam pelo menos uma graduação em licenciatura na área das ciências naturais (Ciências Biológicas, Física e Química), entretanto cinco deles possuem uma segunda graduação. Dessa maneira, encontramos professores também graduados em Geografia, Engenharia de Minas, Geologia, Gestão Ambiental e Pedagogia.

Todos são professores da educação básica, muitas vezes trabalhando em mais de um estabelecimento de ensino, com mais de uma disciplina. Verificou-se que 16 deles lecionam a disciplina de Ciências ( $6^{\circ}$ ao $9^{\circ}$ ano), seis Biologia, dois Física, um leciona Química e um Práticas de Laboratório. Em sua maioria, o grupo é constituído de professores com poucos anos de experiência docente. São 16 com menos de cinco anos, quatro com experiência de cinco a dez anos, um com experiência de 11 a 20 anos e um com mais de 20 anos. Todos são professores de escolas públicas (municipais e estadual), e quatro deles também atuam em escolas particulares.

\section{ANÁLISE DO CORPUS DOCUMENTAL}

Enquanto instrumento norteador para a análise do corpus documental, o quadro de análise de conteúdo resulta de uma combinação robusta entre elementos qualiquantitativos, em que as unidades de contexto são respectivamente vinculadas a uma categoria e a uma subcategoria analíticas. Nesta pesquisa, utilizou-se a condição de exclusão mútua. Portanto, as unidades de contexto foram classificadas uma única vez.

Assim, o Quadro 3 expressa a categorização resultante da análise do corpus documental constituído de atividades de aulas (AA), relatórios finais $(\mathrm{RF})$ e registros em diário de campo (RDC).

Quadro 3 - Quadro da análise das atividades de aulas (AA), dos relatórios finais $(\mathrm{RF})$ e dos registros em diário de campo (RDC).

\begin{tabular}{|l|l|c|c|c|}
\hline \multirow{2}{*}{\multicolumn{2}{|c|}{ Dimensões analisadas }} & \multicolumn{3}{c|}{$\begin{array}{c}\text { Quantidade de unidades } \\
\text { de contexto identificadas }\end{array}$} \\
\cline { 3 - 5 } \multicolumn{2}{|c|}{} & AA & RF & RDC \\
\hline \multirow{2}{*}{$\begin{array}{l}\text { Planejamento } \\
\text { escolar }\end{array}$} & Aspectos burocráticos & 5 & 13 & 45 \\
\cline { 2 - 5 } & Aspectos pedagógicos & 22 & 16 & 40 \\
\hline \multirow{3}{*}{$\begin{array}{l}\text { Potencialidades } \\
\text { didático-pedagógicas }\end{array}$} & O ensino & 22 & 51 & 79 \\
\cline { 2 - 5 } & A possibilidade de aprendizagem & 14 & 32 & 77 \\
\cline { 2 - 5 } & Questões interpessoais & 5 & 7 & 18 \\
\hline \multirow{2}{*}{$\begin{array}{l}\text { Especificidades } \\
\text { do ambiente }\end{array}$} & Preconceitos & 02 & 5 & 15 \\
\cline { 2 - 5 } & Características próprias das trilhas & 13 & 13 & 21 \\
\hline Total & & 83 & 137 & 295 \\
\hline
\end{tabular}

Fonte: elaborado pelos autores, com base em Bardin (2016). 
Conforme expresso pelos professores do curso de extensão universitária, discutir as múltiplas possibilidades didático-pedagógicas das trilhas ecológicas põe em relevância o pensar sobre relações intrínsecas do fazer docente e do espaço florístico natural. Pensar nos potenciais do processo de ensino-aprendizagem ao ar livre, constituído dos meandros de uma trilha, pressupõe uma atividade metacognitiva que busca situar feições organizacionais consideradas importantes à sua exequibilidade.

Nesse sentido, ao se colocar em relevo a categoria planejamento escolar na subcategoria aspectos burocráticos, são elencadas as seguintes inferências: logística organizacional (autorização pelos responsáveis dos estudantes, horários de saída da escola de e chegada, adequação dos horários de aulas, época do ano mais favorável, transporte, alimentação, hidratação etc.) e conhecimento prévio do local da trilha pelos professores organizadores da atividade, ou parte deles. As unidades de contexto a seguir apresentam compreensões acerca desses aspectos:

Sair com uma turma da escola, principalmente quando envolve um lugar de mata ou com água, requer toda uma ginástica. A gente tem que ver autorização, meio de transporte, encaixe de horários, lanche e outras coisas mais. A gente acaba assumindo um certo risco com isso tudo... E isso tem que ser pesado e bem pensado. Por isso que eu acho que, antes de tudo, vale planejar com antecedencia. Discutir os prós e os contras junto com a direção e o setor pedagógico. Acho que uma trilha comę̧a, antes de tudo, na escola. Comę̧a no planejamento. (RDC75 - P3 no quarto encontro do curso)

O professor antes de levar seus alunos para realizar uma trilha é fundamental que tenha um planejamento, pensando e repensando como poderá ser esse momento. Deve conhecer o ambiente, estabelecer em quais pontos fará suas mediaçôes, verificar se o percurso da trilha é adequado para os alunos e analisar as dificuldades que podem ser encontradas desde a saída da escola. (RF11)

No tocante à categoria planejamento escolar na subcategoria aspectos pedagógicos, apontam-se as inferências: opinião dos estudantes acerca da atividade; preparação dos estudantes quanto aos temas a serem explorados durante a trilha; uso de recursos diversificados na preparação dos estudantes; parcerias institucionais para possíveis palestras e orientações; contextualização socioambiental acerca do local da trilha (principalmente para estudantes e professores que ainda não o conhecem in situ); delineamento de recursos voltados à mediação docente durante a trilha e formas de registros estudantis relativos a momentos por eles considerados marcantes; e proposição de atividades relativas ao momento pós-campo. Esses aspectos são expostos nas unidades de contexto adiante:

No começo deste ano [2017] a escola em que eu trabalho no matutino agendou uma visita no Parque da Cachoeira da Fumaça. Os funcionários foram lá na escola e apresentaram o parque usando muitas fotos. Eles também passaram as regras de visitação, principalmente para andar dentro das trilhas. Foi bem legal! A meu ver, foi um momento muito importante, porque acabou sendo um trabalho altamente educativo e deixou todo mundo [professores e alunos] animado em querer visitar o parque. (RDC41 - P11 no terceiro encontro do curso) 
Entendemos que o uso de máquinas fotográficas ou celulares com câmeras são um excelente meio para os alunos registrarem os fatos mais importantes, desde a saida da escola. Durante a viagem, muita coisa pode ser fotografada (relevos e paisagens, por exemplo). Já na trilha, o clique poderá capturar animais, plantas, fungos, solos, rochas e rios, sem precisar coletar partes deles como amostras. ( $\mathrm{RF} 1)$

Quanto à categoria possibilidades didático-pedagógicas na subcategoria o ensino, são elencadas as inferências: utilização de temas educativos gerais e/ou específicos; aplicação de práticas metodológicas diversificadas (tais como experimentações, coleta de amostras, observação e análise in situ etc.); desenvolvimento de projetos pedagógicos multidisciplinares e interdisciplinares; discussão e reflexão cognitiva com base em temas geradores; realização de práticas de ensino no pós-campo; e exigência de condução dos estudantes, com abordagem dialógica e interpretativa, ao longo dos corredores. As unidades de contexto discorrem compreensões acerca desses aspectos: "Quando organizada por vários professores, a aula na trilha pode discutir um assunto central através da interação entre as disciplinas escolares. Sem perder de vista o foco da aula, a trilha ajuda a superar um ensino fragmentado" (RF10).

Até esse curso, eu não tinha pensado em organizar aula numa trilha ecológica. Sei lá... Acho que medo de que algo fugisse do controle. Mas isso [aula na trilha] pode ser algo inovador pra mim e pros alunos. Porque dá pra trabalhar, por exemplo: paisagens, coleta de materiais e até discussão de problemas ambientais. (RDC25 - P13 no segundo encontro do curso)

Ao situar a categoria possibilidades didático-pedagógicas na subcategoria possibilidade de aprendizagem, são enredadas as inferências: aprendizagem conceitual de temas científicos; aprendizagem comportamental pelo contexto da trilha (tais como impactos acerca de hábitos individuais e coletivos quanto à prática de atividades físicas, à alimentação, a consumo de bens e serviços etc.); realização de atividades estudantis no momento pós-campo; e discussão, reflexão e sensibilização ambiental. Nas unidades de contexto a seguir apresentamos compreensões a respeito desses aspectos:

Muitas vezes os alunos apresentam dificuldades em se familiarizar com termos $e$ conceitos cientificos, principalmente quando possuem de forma bem sedimentada definições equivocadas sobre algo. Na trilha, esse problema de aprendizagem pode ser enfrentado quando os alunos têm contato direto [ou bem próximo] com materiais que fazem parte desses termos e conceitos. (RF12)

Durante a caminhada numa trilha ecológica podemos aproveitar para discutir questões ambientais, principalmente as locais. Os alunos ao problematizarem as causas e os efeitos das ações humanas que modificam a natureza, poderão repensar valores sociais que estão na contramão da conservação ambiental. Tal como a ideia de crescimento econômico a qualquer custo, mesmo que, com isso, o meio ambiente seja levado à exaustão. (RF5)

Também, ao enlear a categoria Possibilidades didático-pedagógicas na subcategoria questões interpessoais, são apresentadas as inferências: interação entre professores 
e estudantes no planejamento; interação entre os participantes durante a trilha; e potencial para coletividade, inclusão e socialização estudantil. Nas unidades de contexto adiante apresentamos compreensões sobre esses aspectos: "O planejamento para a trilha deve ser detalhado, com objetivos claros, bem definidos e elaborado com os alunos. O professor estará organizando, mas numa relação próxima com os alunos, para que eles se sintam parte do processo" (AA15).

Eu vejo a trilha como um local de coletividade e inclusão social. Eu falo isso, porque os alunos podem se ajudar durante a caminhada, alertando sobre alguns obstáculos... tipo raizes e galhos. Eles podem ajudar algum colega com deficiência, seja no trajeto da viagem ou durante a própria caminhada. Né? E... Eu vejo que essa interação entre os pares acaba envolvendo, desenvolvendo e incluindo os alunos num grande grupo. (RDC287 - P1 no $8^{\circ}$ encontro do curso)

Ao que se refere à categoria especificidades do ambiente na subcategoria preconceitos, as inferências propositadas são: representação simbólica da trilha a um laboratório; e imaginário estudantil a respeito de trilha ecológica impactado na infância (como um local sombrio, perigoso etc.). As unidades de contexto discorrem compreensões acerca desses aspectos:

A trilha é um laboratório vivo por disponibilizar muitos materiais bióticos e abióticos. Assim, permite traduzir conceitos cientificos para a realidade do aluno. Ela forma lembranças inesqueciveis que os alunos comentam e compartilham durante o restante do ano. (AA17)

“É comum na infância os alunos entenderem a floresta como um local perigoso', como fruto de um imaginário fantasiado por contos, histórias e desenhos animados. A aula na trilha ajuda a desfazer essa visão distorcida sobre as florestas e outras áreas verdes" (AA16).

Ainda, quanto à categoria especificidades do ambiente na subcategoria caracteristicas próprias das trilhas, as inferências apresentadas são: presença de elementos que implicam no processo de ensino-aprendizagem (tais como vegetais, animais, rochas etc.); implicações provocadas pelo ambiente ao ar livre; possibilidades de acidentes físicos; e suscetibilidade do ambiente (poluição, contaminação, queimada e ocupação do solo derivados de ações antrópicas). As unidades de contexto a seguir apontam compreensões acerca desses aspectos:

Eu fiquei surpresa lá na trilha [referindo-se à caminhada na Trilha do Santuário]. O grupo que falou sobre tipos de solo tinha tudo ali. O meu grupo, quando falou de serapilheira, também tinha ali. Era só olhar pros lados, pra baixo, perceber o ambiente, né? Eu penso que a trilha oferece um monte de recursos. A gente é que pode explorar, fazendo a criança pensar, repensar e, com isso, aprender. (RDC278 - P2 no sexto encontro do curso)

Aqui não tem o muro e nem um teto. Tá tudo aberto! A natureza aqui é dispersa! Então gente, eu penso que assim, o céu acaba sendo um recurso pra ser explorado. Dá pra estudar a formação das nuvens, do vento e de outros fenômenos da meteorologia. Inclu- 
sive, estudar como o ser humano de hoje vem alterando e perturbando esses fenômenos. (RDC179 - P5 no quinto encontro do curso)

Assim, as trilhas ecológicas, enquanto produto da tessitura espaço-tempoação, constituem espaços educativos não formais singulares para o processo de ensino-aprendizagem em ciências. Elas proporcionam a mediação do conhecimento in loco, ao ar livre, sem paredes, sujeito a intempéries, imprevistos e surpresas, o que impele aos educadores um olhar acurado acerca de seu planejamento, sua prática (vivência de campo na trilha) e suas iniciativas após a atividade de campo.

Conforme compreensões dos professores, as trilhas, da perspectiva didático-pedagógica, corroboram com a autonomia docente (pressupõem, a priori, responsabilidade e superação de ordem epistemológica e prática), configuram uma proposta motivadora (uma proposta que difere espacial e metodologicamente da sala de aula tradicional) e contribuem para a construção e/ou consolidação de valores socioambientais salutares (o contato com a natureza suscita reflexões axiológicas acerca das ações antrópicas no meio ambiente).

Percebe-se que o fazer didático-pedagógico em uma trilha ecológica exige responsabilidade ética da equipe escolar, uma vez que esse fazer está condicionado à amálgama entre aspectos de segurança e aspectos pedagógicos. Não se pode negligenciar que se trata de uma incursão com estudantes em um ambiente que não oferece, em graus diferentes, as condições nem os suportes estruturais do ambiente escolar. $\mathrm{O}$ ambiente aberto, sujeito a intempéries, exige da equipe escolar mobilização operacional que não pode servir como pretexto (motivo) para escolhas fortuitas, escolhas de locais que prescindam em potencialidades didático-pedagógicas. A responsabilidade ética da equipe escolar deve ir ao encontro de uma escolha acurada, que leve em consideração condições de ordem prática (distância da escola, necessidade ou não de condutor, duração do tempo de viagem e de caminhada ao longo da trilha, segurança na trilha, condicionamento físico necessário à caminhada etc.) e condições de ordem educacionais (potenciais perceptivos e interpretativos da trilha).

Concordando com Pagani et al. (1999), Rendeiro, Santos Júnior e FachinTerán (2012) e Oliveira e Nishida (2011), não se pode refutar o potencial educativo das trilhas ecológicas. Elas materializam ambientes favoráveis à mediação de conhecimentos, à ampliação de percepções e à produção de interpretações do ambiente. Para os autores, as trilhas propiciam complexificação e produção de novos significados sobre aquilo que estudantes e professores já possuem concernente a determinado assunto.

Compreender as trilhas ecológicas como possibilidade didático-pedagógica enriquecedora do processo de ensino-aprendizado em ciências vem ao encontro dos pressupostos expostos por Costa e Mello (2005) e Seniciato (2002), para quem a visita escolar em ambientes florísticos agrega à construção e à consolidação de sentimentos de valoração e pertencimento ao meio ambiente.

Vale destacar que, ao vivenciar a prática de campo em uma trilha ecológica, questões que dizem respeito à sua estrutura física e à do seu entono, a seus pontos interpretativos, a seus níveis de dificuldade e à sua condução devem ser peremptoriamente levadas em consideração. Queiroz et al. (2011) chama a atenção para o fato 
de que, ao se tratar de uma trilha em um espaço não formal não institucionalizado (tal como uma trilha inserida em área particular), conhecer empírica e previamente o local se torna uma exigência ao professor. Nesse caso, a condução por agentes externos à escola pode configurar uma impossibilidade, assim personificando o professor como condutor e mediador da trilha. Desse modo, estudar e captar as potencialidades do ambiente tornam-se pré-requisitos à atividade.

Portanto, apresentamos na Figura 1 uma síntese das compreensões dos professores analisadas sob o sistema de categorização proposto. No formato de esquema operacional, ressaltamos pontos considerados importantes no uso didáticopedagógico de trilhas ecológicas. Tal esquema tem como pressuposto a tentativa de auxiliar professores à organização e ao desenvolvimento de aulas de campo em trilhas ecológicas e salienta pontos tidos como relevantes ligados aos três espaçostempos de uma aula de campo: pré-campo, campo e pós-campo.

No que diz respeito aos potenciais didático-pedagógicos das trilhas, apresentamos na Figura 2 fatores ligados ao processo de ensino-aprendizagem que, implicados pelo ambiente próprio das trilhas (seus elementos bióticos e abióticos,

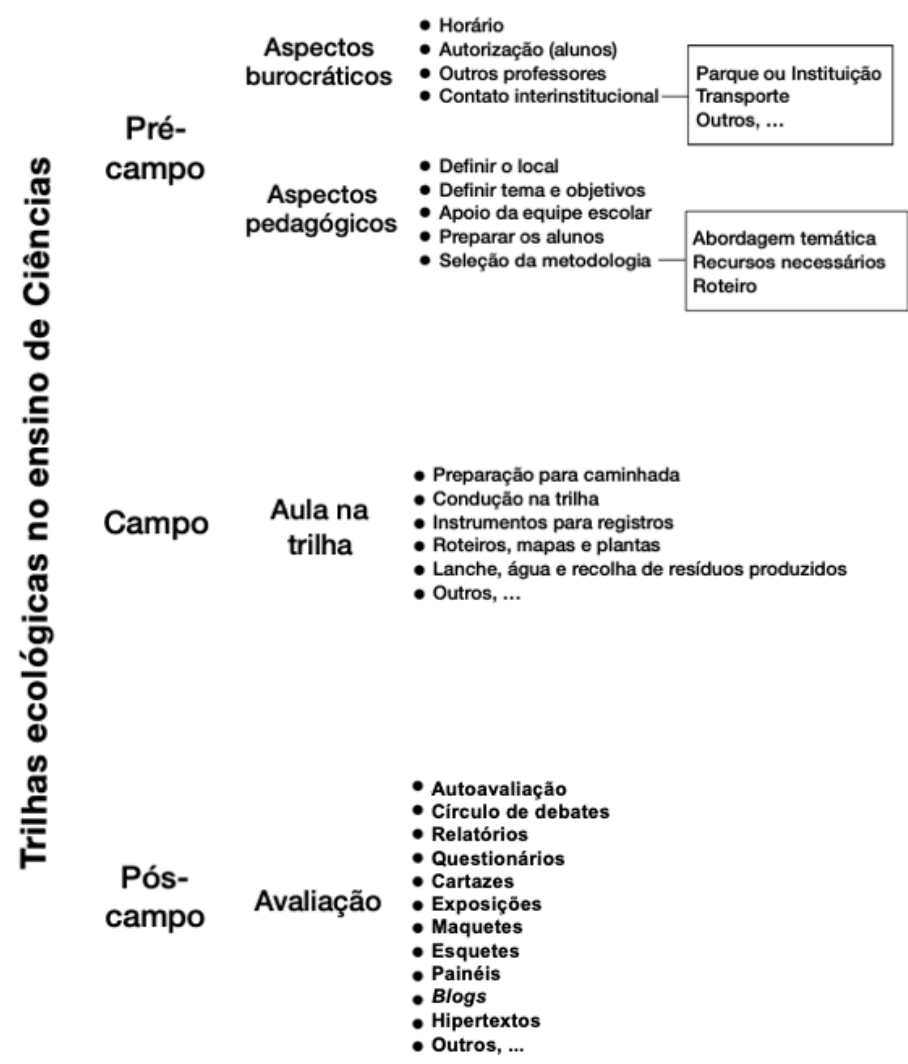

Figura 1 - Esquema operacional que ressalta pontos considerados importantes nos três espaços-tempos de uma aula de campo em uma trilha ecológica: pré-campo, campo e pós-campo. 


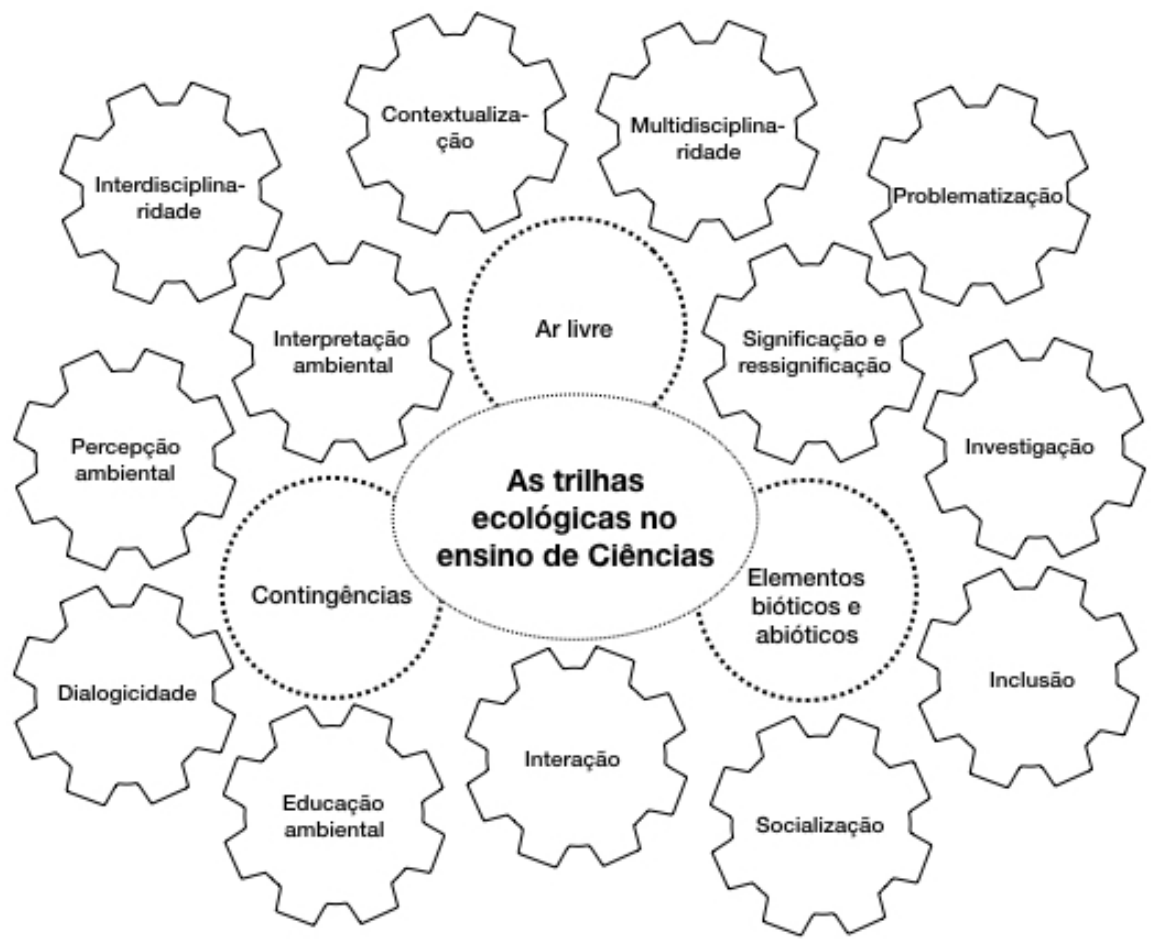

Figura 2 - Fatores ligados ao processo de ensino-aprendizagem que implicam a mediação do professor e de outros possiveis condutores em trilhas ecológicas.

o ar livre e as contingências), podem influenciar a mediação do professor e de outros possíveis condutores. Esses fatores, quando explorados pelo mediador, são potencializados pelo ambiente contribuindo significativamente no desenvolvimento cognitivo, comportamental e emocional dos estudantes. São os fatores: percepção ambiental, interpretação ambiental, socialização, interação, inclusão, multidisciplinaridade, significação e ressignificação, interdisciplinaridade, dialogicidade, educação ambiental, problematização, investigação e contextualização.

A fim de não incorrer a reducionismos interpretativos, chamamos a atenção ao entendimento de que os fatores supracitados devem ser levados em consideração quando de uma aula de campo em uma trilha, não configurando nenhum tipo de obrigação ou imposição. Entretanto, reforçamos que tais fatores sofrem implicações do ambiente próprio das trilhas e, por meio da mediação de quem a conduz, podem ser explorados positivamente no processo de ensino-aprendizagem.

\section{CONSIDERAÇÕES FINAIS}

A pesquisa, por meio do curso Espaços Educativos Não Formais no Ensino de Ciências: as Trilhas Ecológicas em Debate, colocou em relevância, pela voz de professores da educação básica, compreensões e proposições acerca do uso de trilhas 
ecológicas no ensino de ciências. Ao trazer as trilhas para o universo didáticopedagógico se permitiu produzir novas lentes para complexificar o fazer docente no ensino, pois se colocaram em problematização as múltiplas possibilidades desse ensino nos espaços naturais florísticos que perfazem as trilhas. Muitos remanescentes florestais, institucionalizados ou não, foram discriminados e discutidos enquanto espaços educativos potenciais ao ensino de ciências, fosse por já possuírem trilhas abertas e visitáveis, fosse pela possibilidade de virem a tê-las.

Para os docentes, as trilhas aproximam o visitante do ambiente natural, podendo suscitar novos sentimentos que se ligam à possibilidade de reelaborar valores e conceitos. O contato com a natureza pode aproximar as vivências de campo ao currículo escolar, tornando-se, portanto, importante instrumento pedagógico para o desenvolvimento do ensino e permitindo o aprofundamento de conteúdos curriculares e a possibilidade de se alcançar novos conhecimentos. Nas trilhas, o fazer didático-pedagógico pode promover uma situação favorável para discussões sobre temas ambientais, sociais, culturais e econômicos, levando os alunos a uma abordagem desfragmentada e menos abstrata.

Nessa ótica, a pesquisa constituiu um espaço-tempo em que se discutiu o contexto florístico e sociocultural que cerceia o professor e a escola. Muitas falas e entendimentos manifestos vieram ao encontro de Eick (2012) e Oliveira e Nishida (2011), tangenciando o fator da contextualização no ensino de ciências. Muitas colocações convergiram no sentido da importância de o professor utilizar os espaços naturais locais e, na comunidade escolar, buscar os significados atribuídos a esses espaços. Fato considerado relevante quando se propõe desenvolver em trilhas ecológicas práticas educativas mais significativas para os estudantes. Entender aspectos sociais, ideológicos e culturais que ligam os espaços naturais das trilhas ao estudante, à sua família e à comunidade escolar permite, em maior ou menor grau, despertar e/ou consolidar sentimentos de pertencimento ambiental e valores sociais salutares.

Logo, a utilização de trilhas ecológicas no ensino de ciências suscita de forma imanente a produção coletiva de significados e ressignificados sobre elementos materiais (artefatos) e abstratos (mentefatos). Sob outra designação, as trilhas ecológicas podem ser compreendidas como trilhas dialógicas, pois elas, acentuadamente, engendram diálogos entre os seus envolvidos (professores idealizadores, estudantes, comunidade escolar, comunidade de entorno às trilhas, entre outros) antes, ao longo e depois da sua prática de campo. Assim, o fazer didático-pedagógico nas trilhas, complexificado sob diferentes pontos de vista (eis a importância de contrapontos dialógicos), atribui aos mundos físico e social novas associações e interpretações.

\section{REFERÊNCIAS}

BARDIN, L. Análise de conteúdo. São Paulo: Edições 70, 2016.

COSTA, V. C.; MELLO, F. A. P. Manejo e monitoramento de trilhas interpretativas: contribuição metodológica para a percepção do espaço ecoturístico em unidades de conservação. In: SIMPÓSIO NACIONAL SOBRE GEOGRAFIA, PERCEPÇÃO E COGNIÇÃO DO MEIO AMBIENTE, 2005, Londrina. Anais... 2005. 
EICK, C. J. Use of the outdoor classroom and nature-study to support science and literacy learning: a narrative case study of a third-grade classroom. Journal of Science Teacher Education, v. 23, n. 7, p. 789-803, 2012. http://doi.org/10.1007/ s10972-011-9236-1

FREIRE, P. Criando métodos de pesquisa alternativa: aprendendo a fazê-la melhor através da ação. In: BRANDÃO, C. R. (org.). Pesquisa participante. São Paulo: Brasiliense, 1984. p. 34-41.

GONÇALVES, M. L. et al. Fazendo pesquisa: do projeto à comunicação científica. 4. ed. Joinville: Editora Univille, 2014. 120 p.

INSTITUTO BRASILEIRO DE MUSEUS (IBRAM). Guia dos museus brasileiros. Brasília: Instituto Brasileiro de Museus, 2011.

JACOBUCCI, D. F. C. Contribuições dos espaços não formais de educação para a formação da cultura científica. Em Extensão, Uberlândia, v. 7, p. 55-66,2008. Disponível em: http://www.seer.ufu.br/index.php/revextensao/article/view/20390/10860. Acesso em: 25 nov. 2019.

JACOBUCCI, D. F. C.; NOGUEIRA-FERREIRA, F. H.; SANTANA, F. R. Representações de educação não formal e utilização do espaço museal por professoras do ensino fundamental. Ensino em Re-Vista, v. 20, n. 1, p. 125-132, jan./jun. 2013.

LEWIN, K. Action research and minority problems. Journal of Social Issues, v. 2, n. 4, p. 34-36, 1946. https://doi.org/10.1111/j.1540-4560.1946.tb02295.x

MARANDINO, M. et al. A educação não formal e a divulgação científica: o que pensa quem faz? In: ENCONTRO NACIONAL DE PESQUISA EM EDUCAÇÃO EM CIÊNCIAS, 4., 2003, Bauru. Anais... São Paulo: Sociedade Brasileira de Física, 2003. p. 1-13.

MENGHINI, F. B. As trilhas interpretativas como recurso pedagógico: caminhos traçados para a educação ambiental. 2005. 103f. Dissertação (Mestrado em Educação) - Universidade do Vale do Itajaí, Itajaí, 2005.

MOREIRA, M. A. Pesquisa em ensino: aspectos metodológicos. Burgos: Universidade de Burgos, 2003. Disponível em: http://moreira.if.ufrgs.br/pesquisaemensino.pdf. Acesso em: 12 dez. 2019.

NUNES, J. M.; INFANTE, M. Pesquisa-ação: uma metodologia de consultoria. In: ESCOLA POLITÉCNICA DE SAÚDE JOAQUIM VENÂNCIO (org.). Formação de pessoal de nível médio para a saúde: desafios e perspectivas. Rio de Janeiro: Editora Fiocruz, 1996. 224 p. p. 13-36.

OLIVEIRA, S. C. C.; NISHIDA, A. K. A interpretação ambiental como instrumento de diversificação das atividades recreativas e educativas das trilhas do Jardim Botânico Benjamim Maranhão (João Pessoa, Paraíba, Brasil). Turismo - Visão e Ação, v. 13, n. 2, p. 166-185, maio/ago. 2011. https://doi.org/10.14210/rtva.v13n2.p166-185

PAGANI, M. I. et al. As Trilhas Interpretativas da Natureza e o Ecoturismo. In: LEMOS, A. I. G. (org.). Turismo: impactos socioambientais. São Paulo: Hucitec, 1999. p. 12-39. 
PIN, J. R. O.; CAMPOS, C. R. P. As potencialidades pedagógicas na trilha do Santuário. Vitória: Ifes, 2015. (Série Guia Didáticos de Ciências, v. 14).

PIN, J. R. O. et al. Utilização metodológica da pesquisa participante para divulgação cientifica: questões sobre corpo e saúde. Ensino \& Pesquisa, v. 14, n. 2, p. 144-159, jul./dez. 2016. http://doi.org/10.33871/e\%26p.v14i02.912

QUEIROZ, A. C. L. et al. O uso da pesquisa-ação para a avaliação e o aprimoramento de práticas integradas para a vigilância da qualidade da água para consumo humano: potencialidades e desafios. Engenharia Sanitária e Ambiental, v. 17, n. 3, p. 277-286, jul./set. 2012. https://doi.org/10.1590/S1413-41522012000300004

QUEIROZ, R.M. et al. A caracterização dos espaços não formais de educação científica para o ensino de ciências. Revista Areté, Manaus, v. 4, n. 7, p. 12-23, ago./dez. 2011.

REDE NACIONAL DE IDENTIFICAÇÃO DE MUSEUS (RENIM). Museus BR. RENIM, 2017.Disponível em: http://museus.cultura.gov.br/busca/\#\#(global:(enabled :(space:!t),filterEntity:space,map:(center:(lat:20.83141915179677,lng:41.1727452278 1372),zoom:16),openEntity:(id: 9336,type:space)),space:(filters:(En_Estado:!(ES)))). Acesso em: $1^{\circ}$ dez. 2019.

RENDEIRO, M. F. B.; SANTOS JÚNIOR, M. A.; FACHÍN-TERÁN, A. O uso de trilhas para o ensino de ciências. In: SIMPÓSIO EM EDUCAÇÃO EM CIÊNCIAS NA AMAZÔNIA, 2.; SEMINÁRIO DE ENSINO DE CIÊNCIAS NA AMAZÔNIA, 7., 2012, Manaus. Anais... Manaus, 2012.

ROCHA, M. B. R. et al. Estudos sobre trilhas: uma análise de tendências em eventos de Ensino de Ciências e Educação Ambiental. Acta Scientiae, v. 18, n. 2, p. 517-530, maio/ago. 2016.

ROSA, P. R. S. Uma introdução à pesquisa qualitativa em ensino de Ciências. Campo Grande: Universidade Federal do Mato Grosso do Sul, 2013.

SENICIATO, T. Ecossistemas terrestres naturais como ambientes para as atividades de ensino de ciências. 2002.135f. Dissertação (Mestrado em Educação para a Ciência) - Faculdade de Ciências, Universidade Estadual Paulista "Júlio de Mesquita Filho", Bauru, 2002.

THIOLLENT, M. Notas para o debate sobre pesquisa-ação. In: BRANDÃO, C. R. (org.). Repensando a pesquisa participante. São Paulo: Brasiliense, 1999. p. 82-103. THIOLLENT, M. Metodologia da pesquisa-ação. 18. ed. São Paulo: Cortez, 2011. TRIPP, D. Pesquisa-ação: uma introdução metodológica. Educação e Pesquisa, São Paulo, v. 31, n. 3, p. 443-466, set./dez. 2005.

\section{SOBRE OS AUTORES}

José Renato de Oliveira Pin é doutor em ensino de ciência, tecnologia e educação pelo Centro Federal de Educação Tecnológica Celso Suckow da Fonseca (CEFET/RJ). Professor da Prefeitura de Castelo (PC/ES). E-mail:jrtpin@hotmail.com 
Marcelo Borges Rocha é doutor em ciências biológicas pela Universidade Federal do Rio de Janeiro (UFRJ). Professor do Centro Federal de Educação Tecnológica Celso Suckow da Fonseca (CEFET/RJ). E-mail: rochamarcelo36@yahoo.com.br

Recebido em 23 de dezembro de 2019 Aprovado em 25 de maio de 2020 